\title{
Author Correction: Geomorphology: Stressed rocks cause big landslides
}

Peter van der Beek (D)

Correction to: Nature Geoscience https://doi.org/10.1038/s41561-021-00748-7, published online 29 April 2021.

In the version of this News \& Views article originally published, the author's surname was mistakenly given as 'van derBeek' instead of 'van der Beek'; it has now been corrected in the online versions of the article.

Published online: 17 May 2021

https://doi.org/10.1038/s41561-021-00766-5

(c) Springer Nature Limited 2021

\section{Author Correction: Seismology: Unrushed megathrusts}

Daniel Melnick (D)

Correction to: Nature Geoscience https://doi.org/10.1038/s41561-021-00750-z, published online 3 May 2021.

In the version of this News \& Views article originally published, in the standfirst the year of the earthquake was mistakenly given as ' 1868 ' instead of ' 1861 '; it has now been corrected in the online versions of the article.

Published online: 19 May 2021

https://doi.org/10.1038/s41561-021-00772-7

(c) Springer Nature Limited 2021 